\title{
Modelo de susceptibilidad a procesos de remociones en masa en rutas cordilleranas de Chile Central: Ruta 115 CH, Paso Pehuenche, Región del Maule.
}

\section{Susceptibility model to processes of mass removals in cordilleran routes of Central Chile: Route 115 CH, Paso Pehuenche, Maule Region.}

\author{
César Becerra Baeza ${ }^{1}$, Jacqueline De Rurange Espinoza ${ }^{2,3}$
}

\begin{abstract}
Resumen
Se genera e implementa modelo cualitativo-cuantitativo para determinar el nivel de susceptibilidad de remociones en masa en rutas cordilleranas de Chile central, específicamente en ruta $115 \mathrm{CH}$, Paso Pehuenche, Región del Maule. Se aplicó el modelo de susceptibilidad basándose en análisis de terreno y uso de geomática, considerando la interacción de variables físicos-naturales asociados. Se analizaron los procesos geodinámicos con trabajo de campo. Se obtuvo información geomorfológica de modelos de elevación digital (DEM), imágenes satelitales y fotos aéreas. Los resultados obtenidos establecen que existen altas susceptibilidades a deslizamientos, flujos de detritos y desprendimientos de rocas, por las condiciones de geomorfología, rocas altamente meteorizadas, fuertes pendientes, baja cobertura de vegetación y topografía con intervención antrópica, factores óptimos para la generación de estos procesos geodinámicos. La medida de control más eficaz es la prevención, utilizando instrumentos de gestión ambiental territorial. La metodología fue validada con trabajo de terreno en los años 2014 y 2016.
\end{abstract}

Palabras claves: remociones en masa, susceptibilidad, geomática, análisis geomorfológico.

\begin{abstract}
Qualitative-quantitative model is generated and implemented to determine the level of susceptibility of mass removals in cordilleran routes of central Chile, specifically in route $115 \mathrm{CH}$, Paso Pehuenche, Maule region. The susceptibility model was applied based on terrain analysis and the use of geomatics, considering the interaction of associated physical-natural variables. The geodynamic processes were analyzed with fieldwork. Geomorphological information was obtained from digital elevation models (DEM), satellite images and aerial photos. The results obtained establish that there are high susceptibilities to landslides, flows of detritus and rockfalls, duet otheir geomorphology conditions, highly weathered rocks, steep slopes, low vegetation cover and topography with anthropic intervention, optimal factors for the generation of these processes Geodynamic. The most effective control measure is prevention, using instruments of territorial environmental management. The methodology was validated with fieldwork in 2014 and 2016.
\end{abstract}

Keywords: mass removals, susceptibility, geomatics, geomorphological analysis.

Recibido el 02 de febrero de 2018, aceptado el 02 de mayo de 2018.

\footnotetext{
${ }^{1}$ Unidad de Gestión de Información Territorial, Dirección de Planeamiento, Ministerio de Obras Públicas, Región del Maule. 1 oriente 1253, Talca, Chile. E-mail: cesar.becerra@mop.gov.cl

${ }^{2}$ Área Construcción, Ingeniería en Geomensura y Topografía, Universidad Tecnológica de Chile INACAP, Talca, Chile.

${ }^{3}$ Consultora Anaterra www.anaterra.cl
} 


\section{Introducción}

Las remociones en masa son procesos de movilización lenta o rápida de determinado volumen de suelo, roca o ambos, en diversas proporciones, generados por una serie de factores (Hauser, 1994). Según Cruden \& Varnes (1996) son movimientos de una masa de roca, escombros o tierra por una pendiente, bajo la influencia de la gravedad. Este proceso geodinámico es uno de los de origen natural más destructivos que afectan a los seres humanos, causando miles de muertes, daños en las infraestructuras y pérdidas monetarias enormes cada año en todo el mundo (Becerra, 2013; Parise \& Jibson, 2000; Wang \& Peng, 2009; Sabokbar, Shadman, \& Tazik, 2014; Dragićević, Lai, \& Balram, 2015; Hamza \& Kumar, 2017).

El gran porcentaje de las pérdidas por estos procesos naturales son evitables, si el problema se identifica con anterioridad y se toman medidas de prevención o control. Es por esta razón, que el impacto de estos procesos naturales en las actividades humanas, han sido uno de los temas tratados en los últimos años en un amplio número de publicaciones desarrolladas por diversas disciplinas, que caracterizan estos riesgos naturales (Becerra, 2013).

La evaluación de la amenaza implica localizar las áreas inestables, determinando además, el tipo de los movimientos en masa, estableciendo los factores relacionados con la estabilidad y su contribución a la inestabilidad. Según Santacana, Baeza, Corominas, De Paz, \& Marturiá (2003) y Bonachea (2006), las metodologías existentes para la obtención de análisis de áreas susceptibles a remociones en masa no se encuentran estandarizadas, no hay unanimidad en cuanto a la cantidad y tipo de variables a utilizar. Se hace necesario diferenciar el modelo de evaluación de la amenaza, siendo la base el concepto susceptibilidad, el cual se define como el grado de predisposición que tiene un sitio o área en el que se genere una amenaza, debido a sus condiciones intrínsecas y factores detonantes (Becerra, 2006). Este término hace referencia a las características propias que presentan ciertas áreas para que se manifieste la posibilidad de generarse un proceso natural, a través del análisis de los factores condicionantes y desencadenantes, que afectan de diferente forma el desarrollo de estos procesos geodinámicos, determinando el grado de activación del proceso.

Bonachea (2006) explica que las remociones en masa pueden ser analizadas mediante modelos físicos y estadísticos. La búsqueda de correlaciones estadísticas entre factores condicionantes (vegetación, litología, pendiente, orientación, dinámica etc.), desencadenantes (precipitaciones, sismos, actividad humana, etc.) y la ocurrencia de los procesos, permite generar modelos de susceptibilidad a remociones en masa. Así, se han podido obtener modelos de probabilidad espacial bastante satisfactorios, de acuerdo con su validación con cada uno de los factores. La capacidad predictiva de los modelos depende de la calidad de las variables independientes. Santacana et al. (2003) propone la evaluación de susceptibilidad basada en técnicas estadísticas multivariadas en SIG. Mohammadi, Irani, \& Sorur (2014), presenta metodología basada en uso de SIG para el tratamiento de variables condicionantes y detonantes que integra a un modelo numérico. Paz Tenorio, González Herrera, Gómez Ramírez, \& Velasco Herrera (2017), genera una modelación de susceptibilidad a partir del método heurístico con combinación de análisis multicriterio. Dragićević et al. (2015), 
propone una evaluación multicriterio con análisis multiescala para caracterizar la susceptibilidad.

Los modelos que integran susceptibilidad con tratamiento de variables con uso de geomática, parecen los más indicados para el trabajo con procesos naturales que causan desequilibrios entre el medio físico y la actividad humana. El grado de susceptibilidad generalmente se expresa cartográficamente utilizando sombras claras a oscuras o mapas de susceptibilidad de tres, cuatro o cinco clases (Shadman, Rahimi, \& Jafar Beglou, 2014).

El modelo propuesto en este estudio es de corto plazo, debido a que los procesos son de desencadenamiento rápido y no establece la interface entre sequedad y humedecimiento de los materiales a lo largo del año, no incorporando la variable más importante, la precipitación, tanto nival como pluvial. Hauser (1994) indica que el agua es uno de los elementos desencadenantes al originar drásticas disminuciones en la resistencia al corte y presiones intersticiales a lo largo de potenciales planos o superficies de ruptura, situación bastante frecuente y conocida en Chile. Para ello se requiere estudios sobre comportamiento local meteorológico, geomecánica e hidrogeología (observaciones y monitoreo en terreno, sondeos y análisis de laboratorio) para proyectar el comportamiento e interacción de las propiedades físicasmecánicas del suelo y litología.

Las reptaciones y deslizamientos rotacionales, siendo movimientos subsuperficiales, son complejos de analizar con este modelo superficial, por lo que se requiere un tratamiento totalmente distinto con monitoreos multitemporales, análisis de laboratorio y generación topografía al detalle. Es importante señalar que esta investigación determina la localización del proceso por tipo de remoción en masa y entrega una caracterización del grado de activación, para la toma de medidas de prevención.

Los enfoques utilizados en este estudio, son basados en metodologías cualitativas de enfoque heurístico y cuantitativas de enfoque determinístico, dado que representan el trabajo de terreno de variables geomorfológicas (estado suelo-roca) y el uso de herramientas y técnicas geomáticas: Sistema de Información Geográfica,(SIG), Sistemas de Posicionamiento Global,(GPS) y Percepción Remota o Teledetección. Las ventajas del modelo heurístico son referidas a ser un método rápido, razonable y consistente con las condiciones físicas del área de estudio, además, permite contemplar los diferentes factores como un conjunto que incide en la inestabilidad de ladera, atributo del cual carecen otros métodos (Ruff \& Czurda, 2008). La debilidad del método heurístico se encuentra en la subjetividad de los criterios considerados. Van Westen, Castellanos, \& Kuriakose (2008) loentienden como la aproximación más confiable para la elaboración de mapas de susceptibilidad. El método cuantitativo estima el grado de susceptibilidad a través de la cuantificación de cada factor de inestabilidad en valores absolutos, los que son ponderados y estimados mediantes métodos estadísticos (Vranken et al., 2014).

En Chile, los eventos de remociones en masa en zonas cordilleranas son comunes, dada la configuración del relieve, causando graves daños en vidas humanas, infraestructura y bienes materiales (Hauser, 1994). El objetivo principal de este estudio es desarrollar un modelo de análisis de susceptibilidad de procesos de remociones en masa en Ruta Internacional Paso Pehuenche (rol 115-CH), sector Laguna del Maule (figura 1), sobre la base de un modelo de enfoque heurístico- 
determinístico. Se ha seleccionado esta área de estudio debido a que se desarrollan constantemente estos procesos naturales, siendo un corredor bioceánico de gran importancia para la economía regional que une a la República de Chile y la República de Argentina y además se contribuye a una gestión y planificación territorial de riesgos naturales en zonas cordilleranas.

\section{Área de estudio}

El área de estudio está ubicada en zona andina de Chile central, en la ruta internacional 115-CH, Paso Pehuenche, sector Laguna del Maule. La red vial de estudio abarca aproximadamente $26,9 \mathrm{~km}$, desde el $\mathrm{km} \mathrm{133}$, bordeando la laguna, hasta el km 160, cercano al límite internacional de la frontera entre Chile y Argentina. Se encuentra entre las coordenadas geográficas $35^{\circ} 57^{\prime}$ a $36^{\circ} 07^{\prime} \mathrm{S}$ y $70^{\circ} 25^{\prime}$ a $70^{\circ} 37^{\prime} \mathrm{O}$, distante a $130 \mathrm{~km}$ de la ciudad de Talca.
La Laguna del Maule, abarca superficie total de $55,37 \mathrm{~km}^{2}$ y una cuenca de drenaje aproximadamente de $295 \mathrm{~km}^{2}$, su régimen de alimentación es complejo de carácter pluvionivo-glacial. La hidrografía se relaciona con ríos de cursos rápidos, quebradas intermitentes y permanentesy zonas pantanosas asociadas a turberas, bofedales y zonas inundadas por el derretimiento de las nieve.

La geología del sector está constituida principalmente por rocas volcánicas y en menor medida sedimentarias de edad Cenozoica, sobre las cuales se encuentran depósitos no consolidados de origenfluvial, glacial, fluvio-glacial, fluvio-aluvial y coluvial. En estas unidades se encuentran una serie de volcanes y coladas de lava que representan una actividad volcánica desarrollada desde mediados del Pleistoceno hasta elreciente.

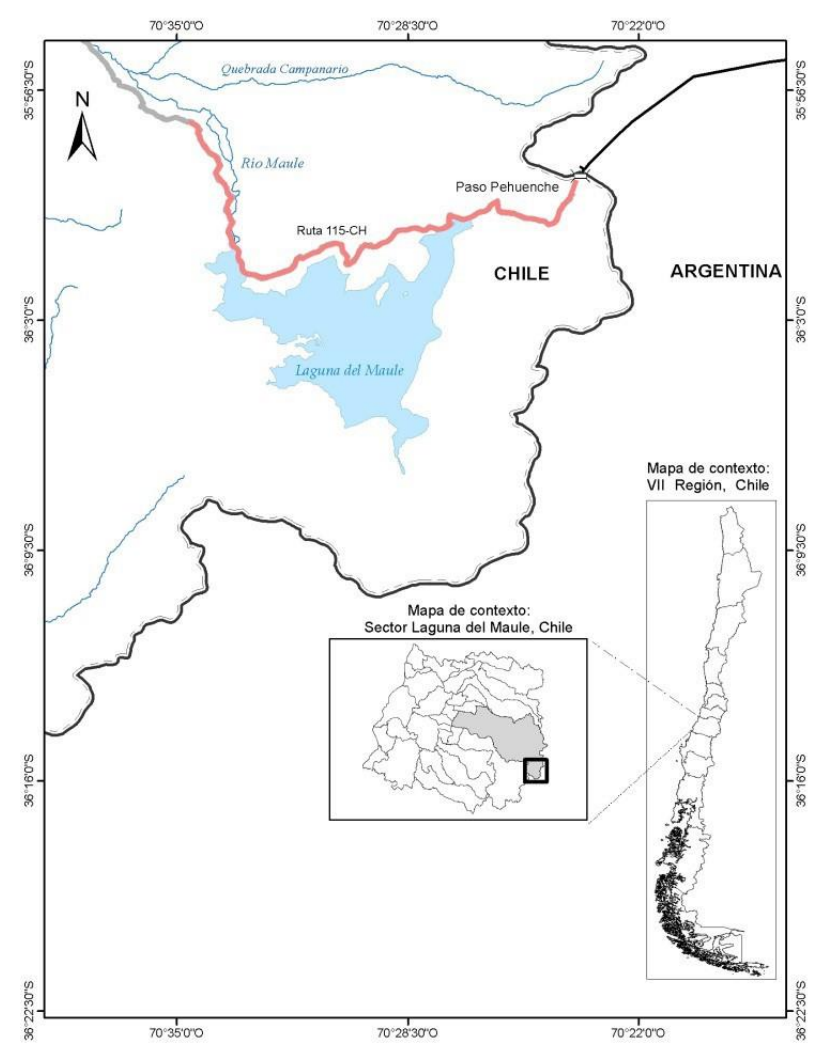

Figura 1. Área de estudio. Fuente: Elaboración propia (2018).

Figure 1. Study area. Source: Own elaboration (2018). 
El clima se encuentra fuertemente influenciado por el efecto que ejerce el relieve sobre el comportamiento climático de la zona, lo cual se manifiesta en toda la región montañosa y particularmente, en el área de estudio. Las precipitaciones invernales son de tipo nival (valores de 1.500 - $2.000 \mathrm{~mm}$ ), manteniéndose acumulación de nieve entre abril y diciembre.

La vegetación, está representada por tres pisos vegetacionales: Matorral bajo mediterráneo andino alto, que corresponde a un matorral bajo, dominado por arbustos espinosos, matorral bajo mediterráneo andino bajo, considerados como elementos florísticos esenciales del sector alto andino del Maule y herbazal mediterráneo andino, que corresponde a un herbazal desértico de hierbas y plantas en cojín muy esparcidas en terreno (Becerra, 2013).

\section{Metodología}

Para el modelo de susceptibilidad, se utilizó una integración entre el método heurísticodeterminístico, en base a identificación de factores que infieren una situación de susceptibilidad de los terrenos a remociones en masa. Se determinó una clasificación de remociones en masa, definida por movimiento, tipo y material comprometido (tabla 1).

Tabla 1

Clasificación de remociones en masa para ambientes cordilleranos. Fuente: Adaptado de Varnes (1978); Hauser (1994); en Becerra (2006)

Table 1

Classification of mass removals for mountain environments. Source: Adapted of Varnes (1978); Hauser (1994) in Becerra (2006)

\begin{tabular}{lll}
\hline Movimiento & Tipo & Material Comprometido \\
\hline Barro/ lodo & $\begin{array}{l}\text { Material fino (fluido viscoso), regolito fino y limo arcilla. } \\
\text { Derrubios, regolito (suelo), pequeñas rocas, residuos }\end{array}$ \\
Flujos/Coladas & $\begin{array}{l}\text { Detritos } \\
\text { (Floques } \\
\text { (Flows) }\end{array}$ & $\begin{array}{l}\text { Decombros). } \\
\text { (escombros) }\end{array}$
\end{tabular}

Detritos

Deslizamientos rocosos (Slide)

Bloques
rocosos/
rocas

Caída de rocas

Derrumbes

Desprendimientos (Falls)

Tierras
Masa de suelo (regolito), derrubios, pequeños a medianos bolones de rocas, superficie del manto o lecho rocoso, arcillas duras, escombros.

Masa de suelo (regolito), detritos de diferente tamaño, masa del sustrato rocoso (una o más unidades), bolones de rocas medianas (derrubios).

Masa del sustrato rocoso (una o más unidades), rodados de rocas medianas (derrubios), detritos medios y regolito, escombros.

Unidades individuales de rocas, bloques sanos y desfragmentados.

Unidades colectivas de rocas, bloques sanos y desfragmentados. Porciones de terreno (suelo/tierra/roca), material fino, regolito fino y limo arcilla, material no consolidado de tamaño muy pequeño.

Dos o más tipos de movimientos. 
Generada la clasificación, se identificó y georrefenció, los tipos de remociones en masa con análisis de fotos aéreas, imágenes satelitales y trabajo de campo. Se identificaron los factores condicionantes que tienen incidencia considerable con la susceptibilidad de este proceso geodinámico, a través de criteriosutilizados en estudios de zonas cordilleranas de Chile central, como la carretera El Cobre perteneciente a la División el Teniente de Codelco-Chile (tabla 2).

Tabla 2

Factores condicionantes. Fuente: Varnes (1978); Hauser (1994); Becerra (2006); De Rurange \& Becerra (2008)

Table 2

Conditioning factors. Source: Varnes, 1978; Hauser, 1994; Becerra, 2006 y De Rurange \& Becerra, 2008

\begin{tabular}{|c|c|c|c|c|c|c|}
\hline \multirow{2}{*}{$\begin{array}{l}\text { Variable } \\
\text { Pendiente }\end{array}$} & \multirow{2}{*}{$\begin{array}{l}\text { Caracterización } \\
\text { Grados }\end{array}$} & \multicolumn{5}{|c|}{ Clases de referencia/ enfoque determinístico } \\
\hline & & $0-10$ & $10-20$ & $20-30$ & $30-45$ & $45-90$ \\
\hline Exposición & Orientación & Sur & $\begin{array}{l}\text { Sureste- } \\
\text { Suroeste }\end{array}$ & $\begin{array}{l}\text { Este- } \\
\text { Oeste }\end{array}$ & $\begin{array}{l}\text { Norteste- } \\
\text { Noroeste }\end{array}$ & Norte \\
\hline $\begin{array}{l}\text { Dinámica de } \\
\text { vertiente }\end{array}$ & Forma-Proceso & $\begin{array}{l}\text { Cóncavo, } \\
\text { depositación }\end{array}$ & Convexo & Declive & $\begin{array}{l}\text { Sector } \\
\text { rectilíneo }\end{array}$ & $\begin{array}{l}\text { Free faces, } \\
\text { caralibre }\end{array}$ \\
\hline Geología & $\begin{array}{l}\text { Unidades } \\
\text { litológicas } \\
\text { superficiales }\end{array}$ & $\begin{array}{l}\text { Depósitos } \\
\text { aluviales y } \\
\text { coluviales no } \\
\text { consolidados }\end{array}$ & $\begin{array}{l}\text { Depósitos } \\
\text { fluvioglaciales y } \\
\text { fluvioaluvionales } \\
\text { no consolidados }\end{array}$ & $\begin{array}{l}\text { Rocas con } \\
\text { alteración } \\
\text { hidrotermal }\end{array}$ & $\begin{array}{l}\text { Rocas } \\
\text { volcánicas } \\
\text { plioceno- } \\
\text { mioceno. } \\
\text { Rocas } \\
\text { volcánicas y } \\
\text { sedimentarias } \\
\text { plioceno- } \\
\text { pleistoceno }\end{array}$ & $\begin{array}{l}\text { Rocas } \\
\text { volcánicas } \\
\text { y coladas } \\
\text { de lava } \\
\text { pleistoceno- } \\
\text { holoceno }\end{array}$ \\
\hline Vegetación & Vigor & Nulo & Bajo & Medio & Alto & Muy Alto \\
\hline \multicolumn{7}{|c|}{ Trabajo de campo / enfoque heurístico } \\
\hline \multicolumn{7}{|c|}{ Erosión y acumulación de material. } \\
\hline \multicolumn{7}{|c|}{ Estado de litología (roca y suelo). } \\
\hline \multicolumn{7}{|c|}{ Acciones antrópicas: consecuencias. } \\
\hline \multicolumn{7}{|c|}{ Permeabilidad (drenaje/humedad). } \\
\hline
\end{tabular}

Para la generación del Modelo Digital de Elevación (DEM), se utilizó el modelo GDEM ASTER, creado a partir de imágenes captadas por el sensor Japonés Advanced SpaceborneThermal Emisionand Reflection Radiometer. Su resolución espacial es de $30 \mathrm{~m}$. Se utilizó imagen satelital Landsat 8 (NASA), con una resolución espacial de $30 \mathrm{~m} \mathrm{y}$ ortofotovuelo SAF-ENDESA, escala 1:40:000 año 2006. Los datos de percepción remota se georreferenciaron en datum mundial WGS84, coordenadas UTM y Huso 19. La cartografía auxiliar utilizada fue la hidrografía, red de caminos y sistema lacustre, escala 1:50.000 del Instituto Geográfico Militar (IGM), año 2010 en datum mundial WGS84, coordenadas UTM y Huso 19. Para el tratamiento de la información satelital, vectorial y ráster se utilizó el programa ArcGis versión 10.1. 
Del modelo ASTER se generó curvas de nivel de equidistancia $25 \mathrm{~m}$. Para la generación del DEM se utilizó el método de interpolación TIN (triangulated irregular network), de acuerdo a lo establecido por Felicísimo (1994). Se generó ráster matricial de tamaño de celda de $25 \mathrm{~m}$. Con esta matriz se originaron capas ráster de pendientes, orientación, sombras y dinámica de vertientes.

Para estudiar la estructura de la vegetación, se construyó el índice de vegetación de diferencia normalizada.Esteíndice relacionó el vigor o estrés de la vegetación, el cual varía entre $-1 \mathrm{y}+1$. (Wang \& Peng, 2009). Para integración de litología superficial, se utilizó capa clasificada por la consultora Infracon (2010 en Becerra, 2013). Se clasificó los datos ráster según clases de referencia en tabla 2 y se determinó el porcentaje que ocupan los rangos más elevados de cada variable utilizada, estableciendo las clases que generan una mayor activación del proceso desde un orden de mayor a menor importancia dentro del área de estudio.

Los datos obtenidos de trabajo de campo (tipos de movimientos, acción antrópica, erosión y acumulación de material, estado de litología, permeabilidad, humedad, etc.), se integran a capa vectorial de tipos de remociones en masa. Integrando los datos ráster y vectoriales, se generó cartografía de susceptibilidad de remociones en masa (Becerra, 2013). En la figura 2 se observa el esquema metodológico para la evaluación de susceptibilidad a remociones en masa.

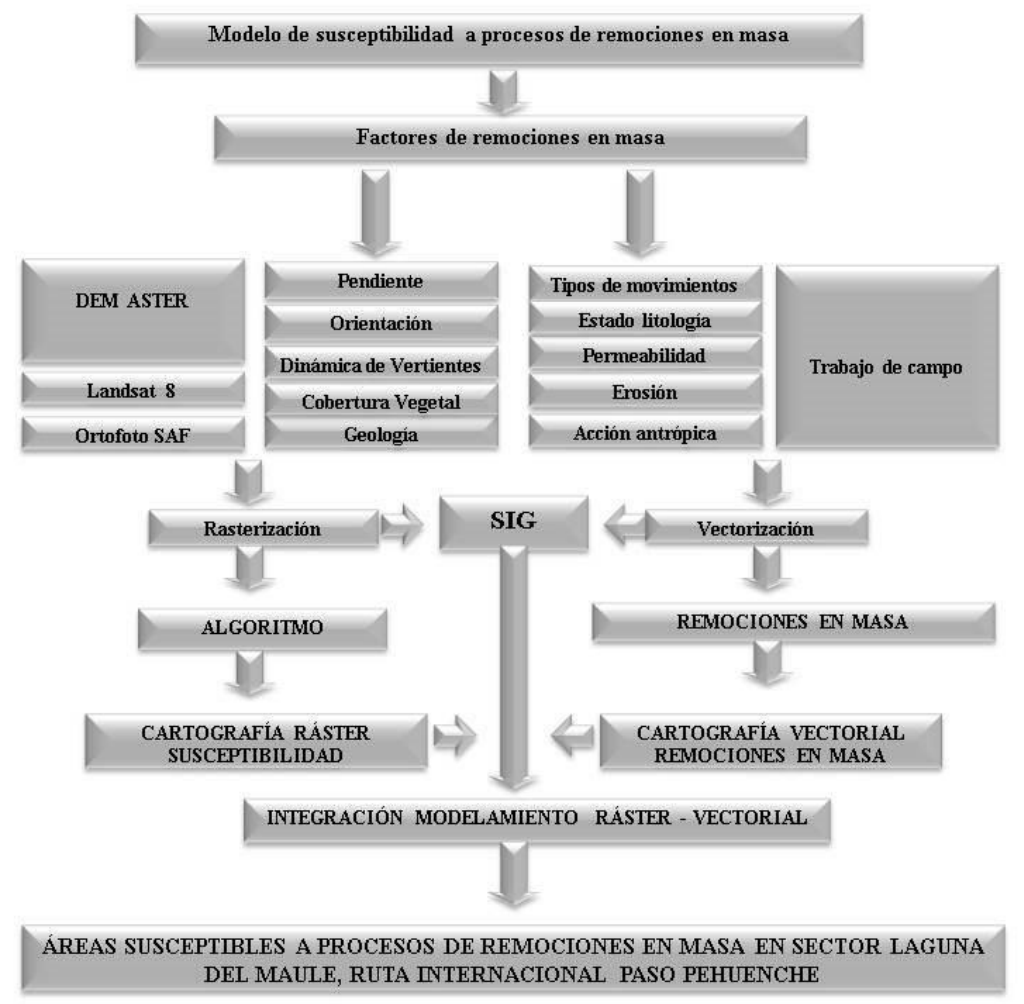

Figura 2. Esquema metodológico para la evaluación de susceptibilidad a remociones en masa. Fuente: Elaboración propia (2018).

Figure 2. Methodological scheme for the evaluation of susceptibility to mass removals. Source: Own elaboration (2018). 


\section{Resultados}

Mediante la aplicación de la metodología, se generaron las cartas temáticas ráster de factores condicionantes, que inciden en la susceptibilidad del modelo de remociones en masa.

En las secciones de inicio y media de la cartografía temática (figura 3), existen pendientes altas $\left(30^{\circ} \mathrm{a} 45^{\circ}\right)$ y muy altas $\left(45^{\circ}\right.$ o más), las que establecen un rol importante en la inestabilidad de ladera determinada por el arrastre de material, desde esas áreas superiores hacia sectores más depresionales.

Se presenta variados tipos de litología del sector de la Laguna del Maule (figura 4), con diferentes tipos de suelo y roca.El estado de la litología superficial, están determinadas en trabajo de campo.

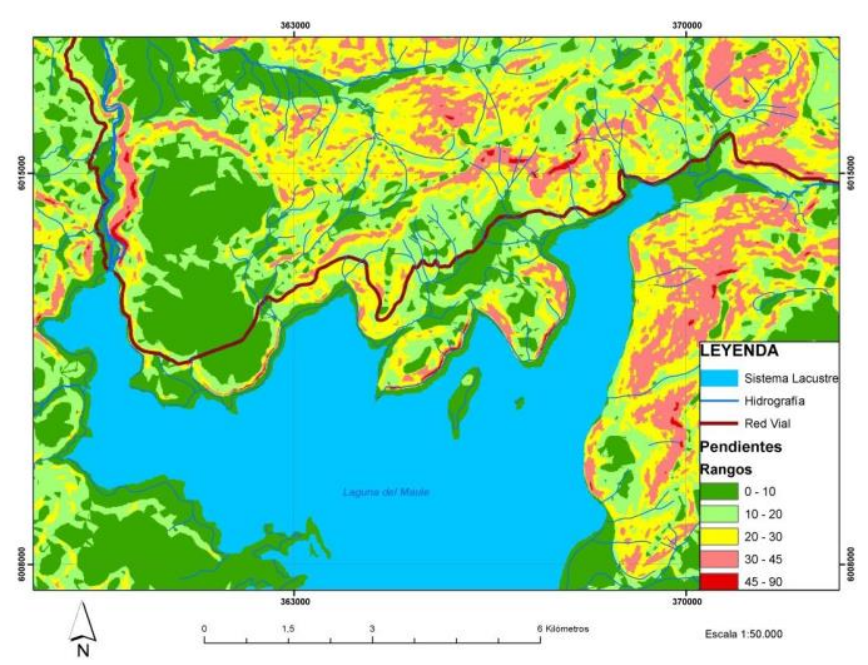

Figura 3. Cartografía de pendientes. Fuente: Elaboración propia (2018).

Figure 3. Slopes map of terrain. Source: Own elaboration (2018).

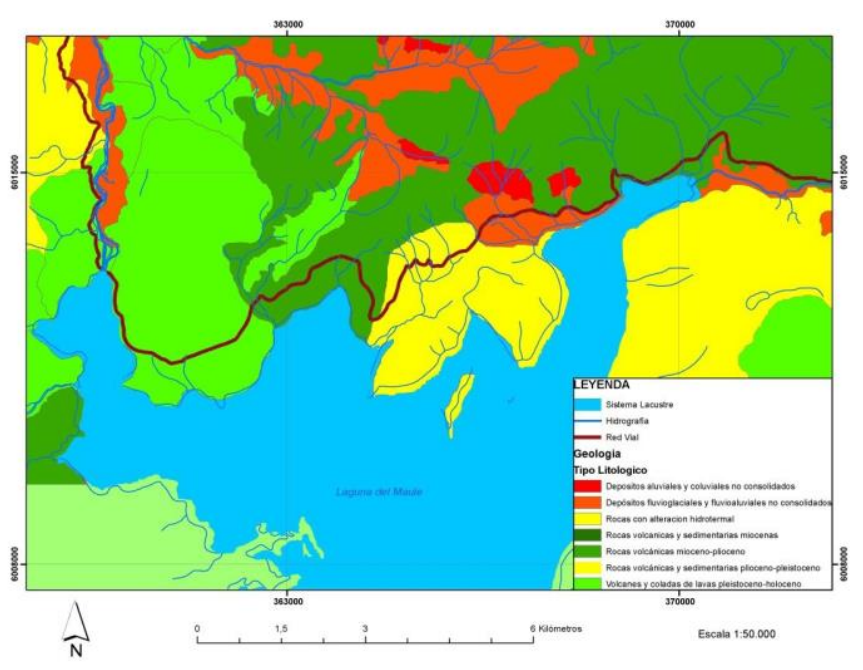

Figura 4. Cartografía de geología. Fuente: Elaboración propia (2018).

Figure 4. Geology map. Source: Own elaboration (2018). 
Los sectores que dominan el área de estudio (figura 5) son los cóncavos y convexos, sobre todo en red vial. En cuanto a los sectores que presentan declive, estos ocupan toda la parte alta, lo que infiere una acumulación de material en dichas partes, considerando los sectores de cara libre (free faces) y rectilíneo, debido a su inclinación y procesos comprometidos (erosión, depositación, lavado superficial, abanicos, flujos y deslizamientos).

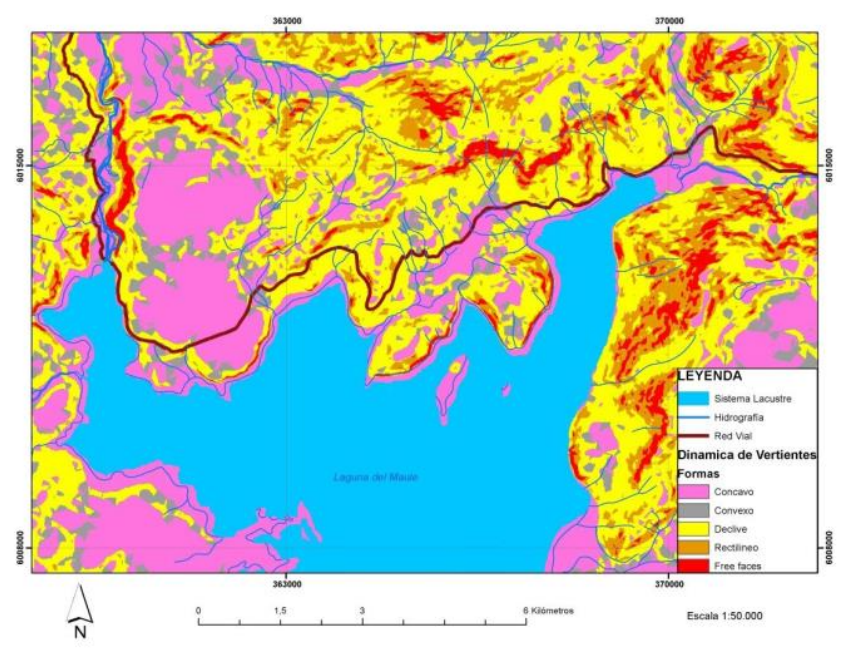

Figura 5. Cartografía de dinámica de vertientes. Fuente: Elaboración propia (2018).

Figure 5. Slope dynamics map. Source: Own elaboration (2018).

Los sectores con vigor de vegetación muy alto (valores 0,75 a 0,6 ) y alto (valores 0,6 a 0,45$)$, están determinados por los cursos de agua, humedad intersicial de los poros por la acumulación nival y umbría (figura 6).

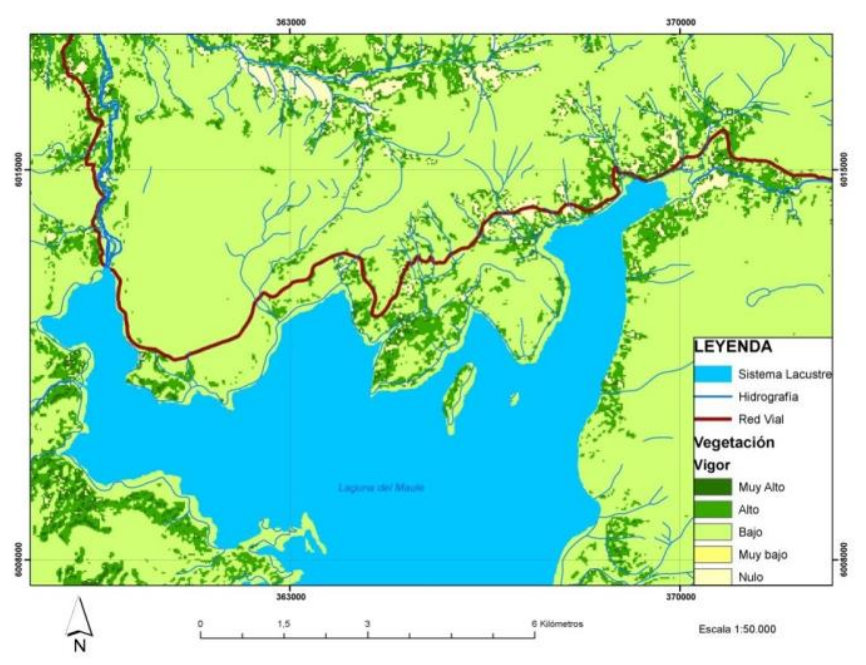

Figura 6. Cartografía de vegetación. Fuente: Elaboración propia (2018).

Figure 6. Vegetation map. Source: Own elaboration (2018). 
En gran parte de la ruta internacional Paso Pehuenche, se determinaron áreas con orientación Sur, Suroeste-Sureste, lo que determina una importante umbría la mayor parte del día. En cambio, los rangos Norte, Noreste y Noroeste manifestaron áreas con mayor insolación, menor cobertura vegetal y mayor erosión superficial (figura 7).

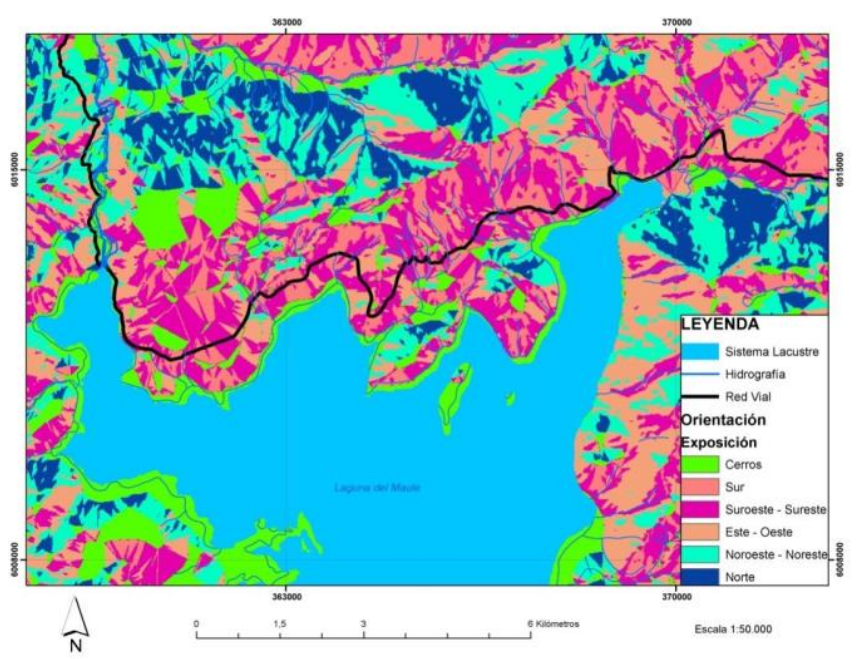

Figura 7. Cartografía de orientación. Fuente: Elaboración propia (2018).

Figure 7. Aspect map. Source: Own elaboration (2018).

\section{Integración de variables ráster al SIG}

Se analizaron las cartas temáticas ráster con el fin de establecer diferentes pesos en porcentajes. De manera estadística se determinó el porcentaje que ocupan los rangos más elevados de cada variable utilizada, estableciendo un orden de mayor a menor importancia (tabla 3). Con cada variable se obtiene el porcentaje de las clases seleccionadas, derivado del total de área de afección de las remociones en masa. Cada porcentaje es ponderado con el porcentaje total de las variables seleccionadas, generando el dato estadístico para el algoritmo ráster.

Tabla 3

Variables y clases en integración ráster. Fuente: Becerra (2013)

Table 3

Factors and classes in raster integration. Source: Becerra (2013)

\begin{tabular}{ll}
\hline Variable & Clases \\
\hline Pendiente & Desde $10^{\circ}$ a $45^{\circ}$ o más. \\
Orientación & Norte; Noreste-Noroeste \\
& Depósitos fluvioglaciales y fluvioaluvionales no \\
Geología & consolidados - Depósitos aluviales y coluviales no \\
Dinámica de vertientes & consolidados \\
Vegetación & Declive, rectilíneo y free faces. \\
\hline
\end{tabular}


En tabla 4, se presentan las áreas de influencia de los rangos de mayor peso de cada variable en estudio y su porcentaje en relación con el total del área de estudio. La ponderación de cada variable permitió establecer su mayor o menor influencia sobre los distintos elementos de las vertientes, potenciando el movimiento o estabilizando los materiales presentes. Susceptibilidad= [pendiente]*33+([dinámica de vertientes]* $31+[$ vegetación $] * 15)+[$ geología $] * 12+$ [exposición]* 9.

\section{Cartografía ráster de susceptibilidad}

La utilización del algoritmo permitió elaborar la zonificación por pixel de la susceptibilidad del sector, para determinar distintos niveles (figura 8). Se obtuvieron cinco rangos en cartografía ráster, mediante la relación de las variables que producen una condición en el proceso geodinámico (figura 9). Las zonas que presentaron una susceptibilidad muy baja, abarcan un área de $8,144 \mathrm{Km}^{2}$, esto corresponde a un $24,91 \%$ del total. En estas zonas, los procesos no se desarrollan con gran magnitud, siendo el más característico la acumulación de material de sedimentos, detrítico fino y grueso, el cual no confiere mayores daños o problemas a la vía de comunicación. Aquellas zonas que presentaron una susceptibilidad baja, ocupan un área de $10,518 \mathrm{Kmh}$, lo cual corresponde a un 32,18\% del total. En estas zonas predominan procesos erosivos débiles. Tampoco se desarrollan movimientos de material de gran magnitud que puedan provocar problemas a la vía de comunicación.

\section{Rangos y porcentaje ocupado por susceptibilidad de remociones en masa}

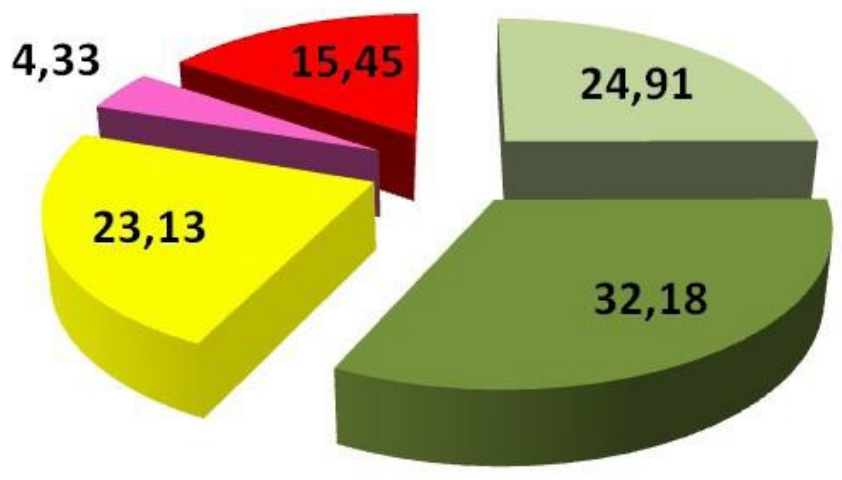

Muy Bajo

Bajo

Medio

Alto

Muy Alto

Figura 8. Rangos, área de influencia y porcentaje ocupado por susceptibilidad ráster de remociones en masa. Fuente: Elaboración propia (2018).

Figure 8. Ranges, area of influence and percentage occupied by raster susceptibility of mass removals. Source: Own elaboration (2018). 
Tabla 4

Susceptibilidad, rangos, área de influencia y porcentaje ocupado por las variables de pendiente, orientación, geología, dinámica de vertientes y vegetación. Fuente: Adaptado de Becerra (2013)

Table 4

Susceptibility, ranges, area of influence and percentage occupied by the variables of slope, aspect, geology, slope dynamics and vegetation. Source: Adapted from Becerra (2013)

\begin{tabular}{|c|c|c|c|c|c|c|c|c|c|c|c|c|c|c|c|}
\hline \multirow{2}{*}{$\begin{array}{l}\begin{array}{l}\text { Susceptibilidad } \\
\text { ráster }\end{array} \\
\text { Clasificación }\end{array}$} & \multicolumn{3}{|c|}{ Pendiente } & \multicolumn{3}{|c|}{ Orientación } & \multicolumn{3}{|l|}{ Geologia } & \multicolumn{3}{|c|}{ Dinámica de vertientes } & \multicolumn{3}{|c|}{ Vegetación } \\
\hline & Rango & $\begin{array}{l}\text { Área } \\
\mathrm{km}^{2}\end{array}$ & $\%$ & Rango & $\begin{array}{l}\text { Área } \\
\mathrm{km}^{2}\end{array}$ & $\%$ & Rango & $\begin{array}{l}\text { Área } \\
\mathrm{km}^{2}\end{array}$ & $\%$ & Rango & $\begin{array}{l}\text { Área } \\
\mathrm{km}^{2}\end{array}$ & $\%$ & Rango & $\begin{array}{l}\text { Área } \\
\mathrm{km}^{2}\end{array}$ & $\%$ \\
\hline Muy bajo & $0^{\circ}-10^{\circ}$ & 8,987 & 26,12 & Sur & 7,383 & 21,68 & $\begin{array}{l}\text { Volcanes y coladas } \\
\text { de lavas pleistoceno - } \\
\text { holoceno. }\end{array}$ & 6,674 & 19,45 & Cóncavo & 7,388 & 20,86 & $\begin{array}{l}\text { Muy } \\
\text { alto }\end{array}$ & 5,274 & 15,41 \\
\hline Bajo & $10^{\circ}-20^{\circ}$ & 10,762 & 31,28 & $\begin{array}{l}\text { Suroeste- } \\
\text { Sureste }\end{array}$ & 11,631 & 34,15 & $\begin{array}{l}\text { Rocas volcánicas } \\
\text { plioceno - mioceno/ } \\
\text { sedimentarias } \\
\text { miocenas }\end{array}$ & 15,666 & 45,66 & Convexo & 3,451 & 9,75 & Alto & 5,876 & 17,16 \\
\hline Medio & $20^{\circ}-30^{\circ}$ & 9,42 & 27,38 & $\begin{array}{l}\text { Este- } \\
\text { Oeste }\end{array}$ & 7,795 & 22,89 & $\begin{array}{l}\text { Rocas con alteración } \\
\text { hidrotermal } \\
\text { Volcánicas } \\
\text { sedimentarias } \\
\text { plioceno y mioceno }\end{array}$ & 2,8604 & 8,34 & Declive & 16,763 & 47,34 & Bajo & 11,087 & 32,38 \\
\hline Alto & $30^{\circ}-45^{\circ}$ & 5 & 14,53 & $\begin{array}{l}\text { Noreste- } \\
\text { Noroeste }\end{array}$ & 3,79 & 11,13 & $\begin{array}{l}\text { Depósitos } \\
\text { fluvioglaciales y } \\
\text { fluvioaluvionales no } \\
\text { consolidados. }\end{array}$ & 4,351 & 12,68 & Rectilineo & 4,668 & 13,18 & $\begin{array}{l}\text { Muy } \\
\text { bajo }\end{array}$ & 2 & 5,84 \\
\hline Muy Alto & $45^{\circ}-90^{\circ}$ & 0,237 & 0,69 & Norte & 3,461 & 10,16 & $\begin{array}{l}\text { Depósitos aluviales } \\
\text { y coluviales no } \\
\text { consolidados. }\end{array}$ & 4,761 & 13,88 & $\begin{array}{l}\text { Cara libre } \\
\text { Free } \\
\text { faces) }\end{array}$ & 3,143 & 8,88 & Nulo & 9,998 & 29,20 \\
\hline \multicolumn{3}{|c|}{$\begin{array}{l}\text { Relación mayores Incidencias de peso } \\
(\%)\end{array}$} & 73,88 & 21,289 & & & 26,556 & & & 69,393 & & & \multicolumn{3}{|l|}{35,046} \\
\hline \multicolumn{3}{|c|}{$\begin{array}{l}\text { Algoritmo: porcentaje de cada variable } \\
(\%)\end{array}$} & 33 & 9 & & & 12 & & & 31 & & & \multicolumn{3}{|l|}{15} \\
\hline
\end{tabular}


Las zonas que presentaron una susceptibilidad media, poseen una superficie de $7,560 \mathrm{Km}^{2}$, lo que representa un $23,13 \%$ del total. La susceptibilidad media indica el inicio de procesos de movimientos de material, tanto de suelo y roca. El principal proceso vinculado en estas áreas son los deslizamientos de material, tanto de detritos y bloques rocosos.

En cuanto a las zonas que presentaron susceptibilidad alta, estas ocupan una superficie de $1,416 \mathrm{Km}^{2}$, esto corresponde a un $4,33 \%$ del total. Aunque no es tan representativo como el rango anterior, los principales procesos están vinculados a transporte de material de suelo y derrubios, además la acción del agua superficial y subsuperficial, genera procesos de flujos y el transporte de material como conos de deyección. Debido a los procesos vinculados, es de los sectores que presenta mayores problemas para la vía de comunicación.

Por último, aquellas zonas que presentan una susceptibilidad muy alta, poseen un área de $5,049 \mathrm{Km}^{2}$, cifra que corresponde a un $15,45 \%$ del total. Estas zonas ocupan una superficie importante, además se desarrollan procesos de mayor velocidad, movimientos de material como bloques rocosos, deslizamientos y flujos. Estas zonas son las que presentan una mayor probabilidad de ocurrencia de procesos de remoción en masa, lo que la convierte en la zona con mayor daño o problemas a la vía de comunicación.

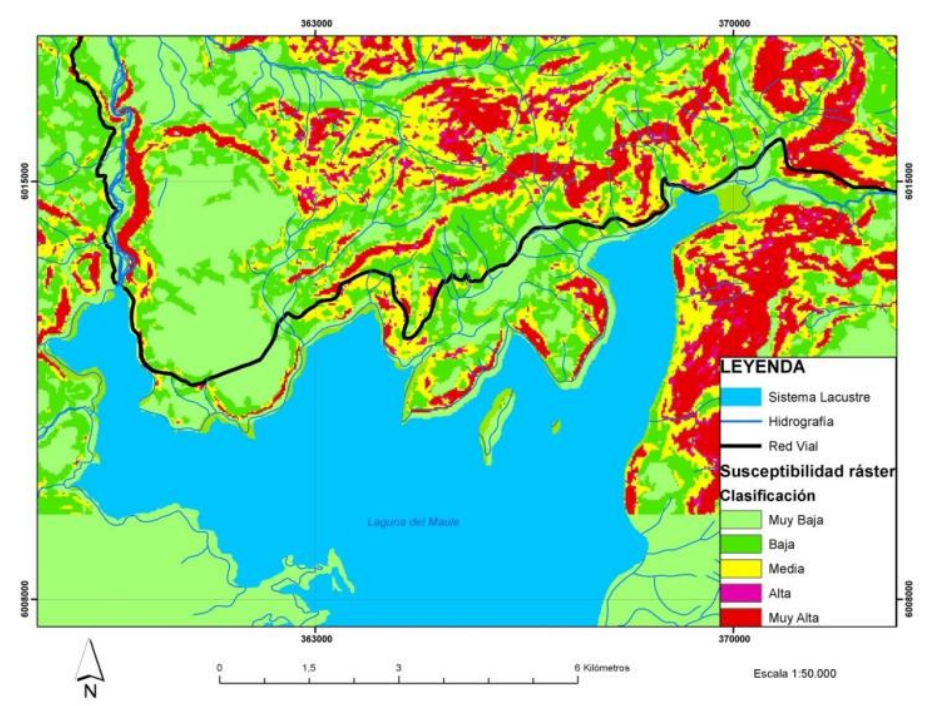

Figura 9. Cartografía ráster de susceptibilidad. Fuente: Elaboración propia (2018).

Figure 9. Raster susceptibility map. Source: Own elaboration (2018).

\section{Cartografia de tipos de remociones en masa}

Mediante trabajo de campo y uso de SIG, se identificó y zonificó los diferentes procesos de remociones en masa. Se obtuvo 8 tipos, según clasificación desarrollada (tabla 1). Con respecto a la cantidad de procesos en el área de estudio, se cuantificaron 52 áreas (figura 11). 
De los procesos de remociones en masa mencionados, los que manifiestan una gran predominancia en el área, son los deslizamientos de tipo detrítico y bloques de roca, con $40,3 \%$ del total cuantificado (tabla 5). Estos procesos son los que transportan mayor cantidad de material en el borde del camino. Siguen los tipos de remociones en masa caóticos o complejos con un $19,2 \%$, también generando cantidad considerable de material (detritos, suelo y roca). Los flujos de detritos, coladas de barro/lodo y coladas de bloques rocosos/rocas, están relacionados con los cursos de agua de tipo intermitente y generan problemas de colmatación en las obras de arte. Las remociones en masa que abarcan mayor superficie son los deslizamientos. Estos procesos son los que presentan la mayor cantidad de material al momento de la activación, en función de los factores y las condiciones en que se encuentren cada área.

Tabla 5

Tipos de Remociones en masa y cuantificación en área de estudio. Fuente: Elaboración propia (2018)

Table 5

Types of mass removals and quantification in the study area. Source: Own elaboration (2018)

Proceso

Cantidad

Caóticos/complejos 10

Deslizamientos de detritos

Deslizamientos de detritos y bloques rocosos

Desprendimientos/Derrumbes

Desprendimientos/caídas de rocas

Flujos/coladas de barro/lodo

Flujos/coladas de bloques rocosos/rocas

Flujos de detritos

Los deslizamientos de detritos y bloques rocosos, se manifiestan en altura considerable con respecto a los otros procesos de remociones en masa, aportando material compacto a la ladera, caracterizado por una meteorización rápida de la formación rocosa, y que se puede apreciar por la gran cantidad de pequeños materiales compactos que se encuentran al pie de ladera y talud (figura 10). Los desprendimientos/caída de rocas y derrumbes, son los que representan los más grandes bloques de material compacto; aunque son representados en altura, igual hay presencia de este tipo de movimiento en áreas con menor altura. 

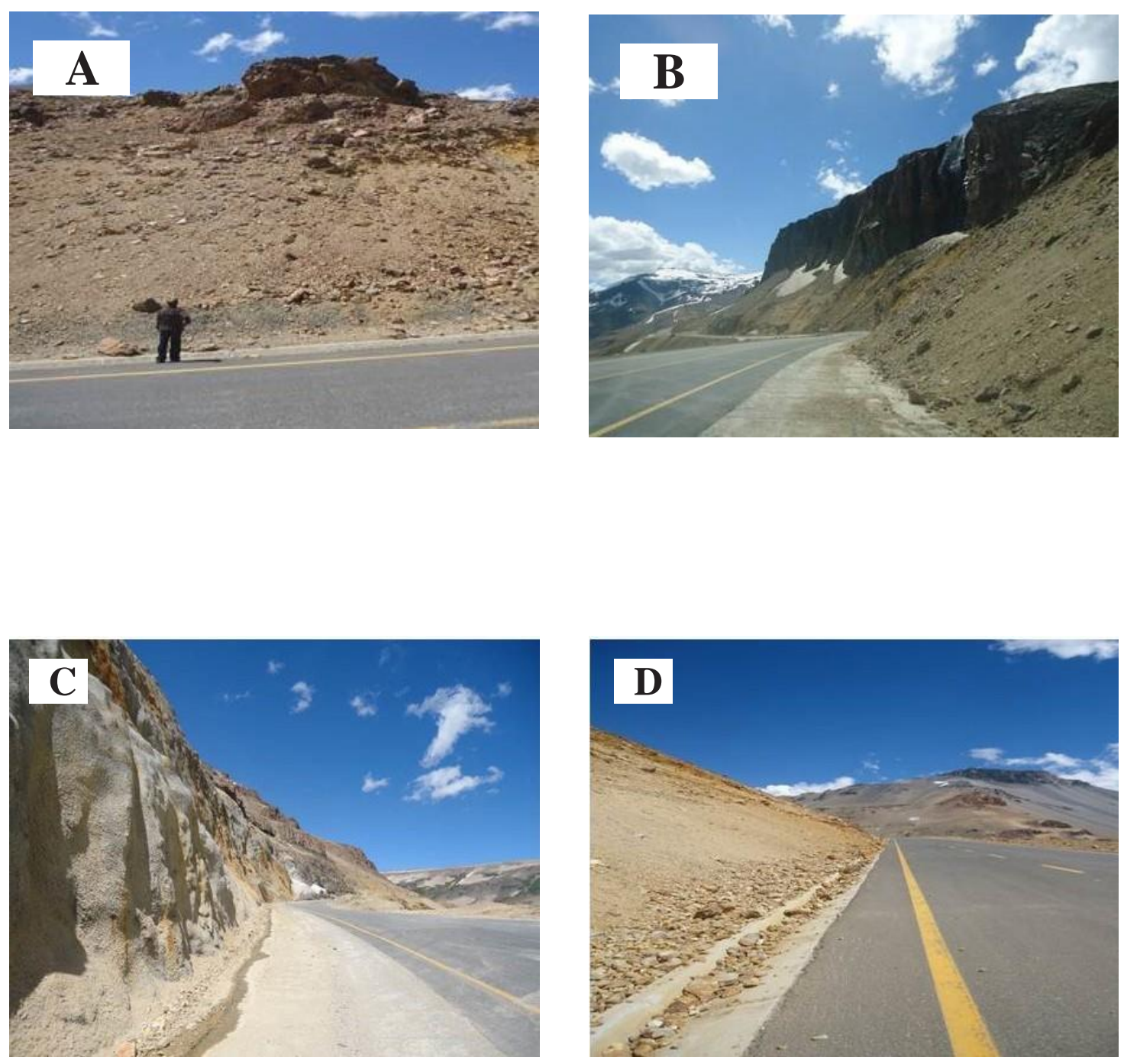

Figura 10. Deslizamientos de detritos y bloques rocosos, sector Cuesta La Zorra, Km 156, 200 al 156, 450 aprox. Punto GPS: Datum WGS 84; N 6.014.827-E 372.646 (figura 11). Macizo rocoso con alta meteorización y pendiente muy alta cercana a ruta. A) Deslizamientos de bloques rocosos de diferentes tamaños y pequeños desprendimientos de rocas. B) Vista de talud que presenta alta pendiente con deslizamientos de material. C) Talud con obras de mitigación que presentan oxidación en algunas áreas con meteorización física importante. D) Talud con gran cantidad de material cercano a camino. Fuente: Dirección de Planeamiento (DIRPLAN) (2014).

Figure 10. Slides of detritus and rocky blocks, Cuesta La Zorra sector, Km 156, 200 to 156, 450 approx. GPS Point: Datum WGS 84; N 6,014,827-E 372,646 (figure 11). Rocky massif with high weathering and very high slope close to the route. (A) Slides of rocky blocks of different sizes and small rock slides. B) View of right slope that presents high slope with landslides of material. C) Slope with mitigation works that present oxidation in some areas with important physical weathering.

D) Slope with a large amount of material close to the road. Source: DIRPLAN (2014). 


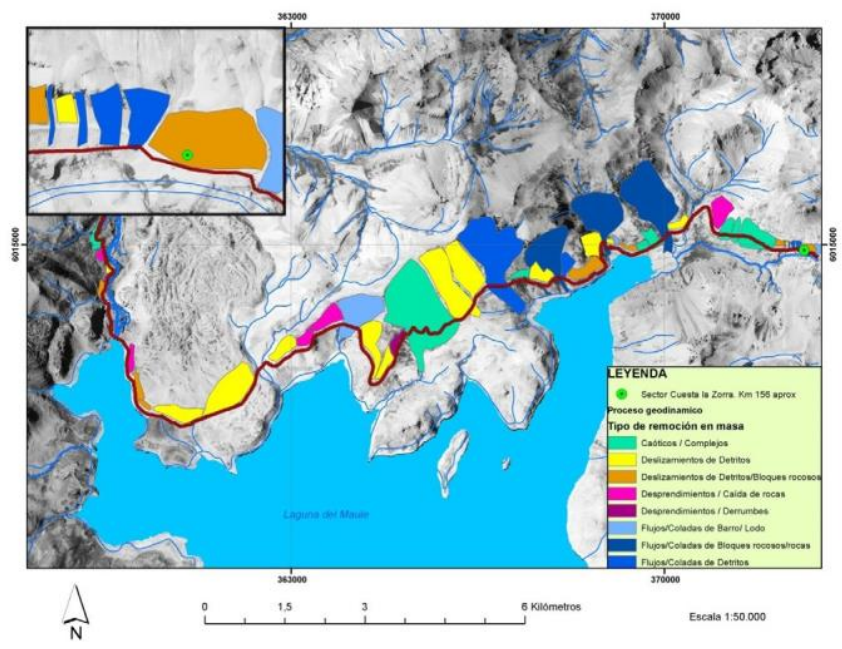

Figura 11. Cartografía de tipos de remociones en masa sobre ortofotovuelo SAF-ENDESA y punto de caracterización de terreno sector Cuesta la Zorra. Fuente: Elaboración propia (2018).

Figure 11. Cartography of types of mass removals on orthophoto flight SAF-ENDESA and point of characterization of land sector Cuesta la Zorra. Source: Own elaboration (2018).

Integración de cartografía de remociones en masa y susceptibilidad ráster.

La cartografía de tipos de remociones en masa, se integra a la cartografía de susceptibilidad ráster, mediante método estadístico bivariante, definiendo mediante los porcentajes más altos de susceptibilidad ráster y los datos de caracterización heurística de trabajo de campo, la clasificación de susceptibilidad por tipo de remociones en masa (figura 12).

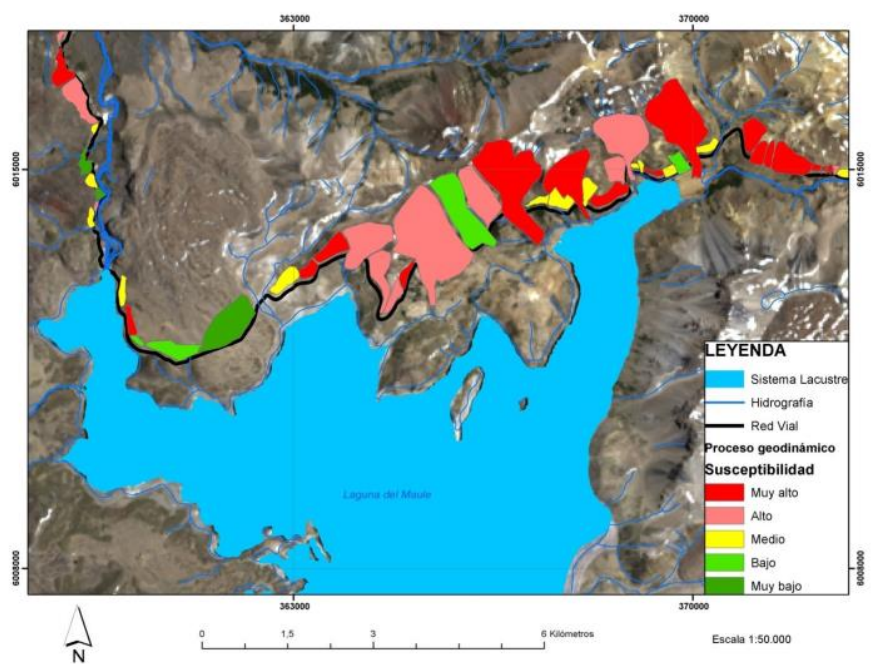

Figura 12. Cartografía de susceptibilidad de remociones en masa sector Laguna del Maule, Paso Pehuenche. Fuente: elaboración propia en base a imagen satelital Landsat 8. Fecha de adquisición 28/12/2017.

Figure 12. Map of susceptibility to mass removals in the Laguna del Maule sector, Paso Pehuenche.

Source: own elaboration based on satellite image Landsat 8. Date of acquisition 28/12/2017 


\section{Clasificación de la susceptibilidad}

Susceptibilidad muy alta: Se determinaron 20 áreas con alto potencial de activación. Este tipo de susceptibilidad, determina tipos de remociones en masa con movimientos de material rocoso fracturado, como lo son los desprendimientos y deslizamiento de detritos, aunque hay presencia de remociones en masa del tipo caóticas y flujos de detritos, barro y bloques rocosos (figura 12), que activan materiales ya sean, finos o gruesos.

Con respecto a la pendiente, las áreas se caracterizaron por tener una pendiente mayor a $40^{\circ}$, aunque esta variable no influye demasiado en los flujos detríticos, pero tiene una gran implicancia en los deslizamientos de detritos y bloques rocosos, desprendimientos/ caídas de rocas y los del tipo caótico. Muy relacionada con esta variable está la dinámica de vertientes debido a la morfología de free faces y rectilíneo, característicos de este tipo de graduación.

La cobertura vegetal incidió bastante en que las áreas presentaran este tipo de susceptibilidad, al no poseer una barrera natural que disminuyera su activación. Las áreas presentaron casi nula existencia de este factor. Muy ligada con esta variable está la exposición, siendo la incidencia del proceso la que infiere sectores con menor grado de vigor de la vegetación, íntimamente relacionado también con la erosión superficial.

$\mathrm{Al}$ igual que la cobertura vegetal, la erosión es un factor determinante para la adopción de áreas con este tipo de graduación. Este tipo de susceptibilidad se da principalmente en las unidades litológicas correspondientes a los depósitos aluviales y coluviales no consolidados, ya que la naturaleza del material presenta una gran retención de agua, aunque en toda el área de estudio dominan las rocas volcánicas plioceno-mioceno y rocas volcánicas y sedimentarias pliocenopleistoceno, que presentan un alto grado de meteorización (figura 13), aunque también este tipo de susceptibilidad ocurre en flujos de detritos, generándose en cualquier tipo de litología. La acción antrópica es de alta intervención, lo que determina un aumento en estagraduación.
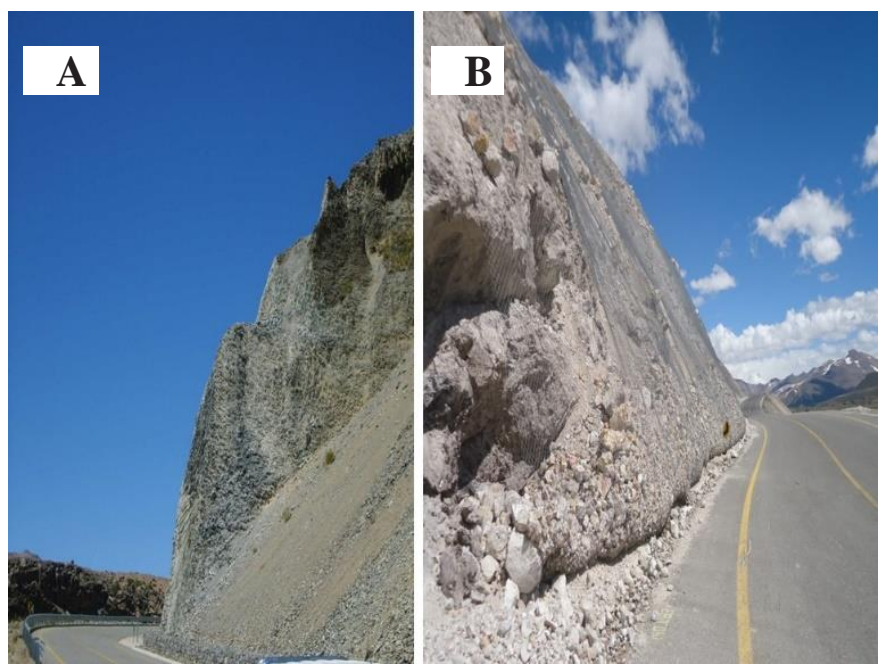

Figura 13. A) Vista de talud que presenta alta pendiente con desprendimientos y deslizamientos de bloques rocosos de diferentes tamaños. B) Talud con caída de rocas y pequeños bloques rocosos en mallas de mitigación. Fuente: Trabajo de campo (2016).

Figure 13. A) View of slope that presents high slope with landslides and landslides of rock blocks of different sizes. B) Slope with falling rocks and small rock blocks in mitigation meshes. Source: Field work (2016). 
Susceptibilidad alta: Para este tipo de susceptibilidad, se determinaron 11 áreas de diferentes tipos de remociones en masa. La pendiente fue considerada por encima de los $30^{\circ}$, por lo que es un indicador apropiado de esta graduación en movimientos de material. La cobertura vegetal se determinó entre escasa y nula, lo que demuestra que las áreas disminuyeron su porcentaje en susceptibilidad en comparación a la más alta graduación, por esta especial condición natural.

Muy ligada con esta variable esta la exposición, siendo la incidencia de este proceso la que induce sectores con menor grado de erosión y de vigor de la vegetación. En esta misma condición se encuentra la erosión, que se determinó entre las designaciones de severa y muy severa, por lo que la erosión de material y su disminución en la acumulación, genera áreas en donde la susceptibilidad baja un cierto grado, comparado con las áreas en donde la cobertura sea nula y la erosión severa. Se identificaron unidades litológicas correspondientes a depósitos aluviales y coluviales no consolidados, rocas volcánicas plioceno-mioceno, rocas volcánicas y sedimentarias plioceno-pleistoceno con alta meteorización. La acción antrópica es de alta intervención, lo que determina un desarrollo alto de esta graduación.

Susceptibilidad media: Se determinaron 14 áreas de diferentes tipos de remociones en masa, con casi la totalidad de los movimientos y con este tipo de susceptibilidad. Los factores condicionantes implican una considerable baja en la activación de susceptibilidad. La pendiente $\left(20^{\circ}-30^{\circ}\right)$ genera movimientos de material superficial, pero más estables comparados con susceptibilidades altas. Con respecto a la cobertura vegetal, ésta principalmente se manifiesta entre escasa y moderada, lo que debilita los procesos. La litología en algunos sectores esta meteorizada. Con respecto a dinámica de vertientes se mantiene estable. La erosión es mediana y la acción antrópica puede inducir alguna dinámica.

Susceptibilidad baja: Se determinaron 4 áreas de susceptibilidad baja. Las variables de activación implican una baja en la susceptibilidad de que se active una remoción en masa, ya que solo la presencia de la cobertura vegetal está clasificada en moderada y la erosión es baja, lo cual disminuyen considerablemente el proceso geodinámico. La pendiente genera pequeños movimientos de material superficial. Las unidades litológicas superficiales presentes para este tipo de susceptibilidad son los lahares, brechas volcánicas andesíticas y andesitas, estas dos últimas son las que presentan la mayor tendencia a no activar en largos periodos de tiempo las remociones en masa que presentan esta susceptibilidad, por exponer un grado de meteorización y fractura de roca baja, alta cohesión y baja permeabilidad, por lo tanto el estado litológico es estable. En este sentido también, la acción antrópica no se presenta muy activa como en las demás áreas, por lo tanto, todos estos factores tienden a disminuir en grandes rangos la susceptibilidad del proceso geodinámico.

Susceptibilidad muy baja: Esta susceptibilidad se presentó en 3 áreas de remociones en masa. No representan una importancia para zonificarse en este tipo de estudio. Las zonas tratadas se consideraron como áreas estables y en su mayoría están establecidas las infraestructuras, tanto las instalaciones como las vías de comunicación.

\section{Discusión}

Se presentaron correlaciones con la ocurrencia de remociones en masa para 
las variables de mayor importancia en el algoritmo ráster: dinámica de vertientes y pendientes. Estas características inciden en la velocidad, energía y volumen de las remociones que puedan originarse. Así también, cualquier modificación de ellos puede transformar una ladera estable en inestable y generar movimientos de material. Haeri y Samiei (1996 en Sabokbar et al., 2014) considera que la pendiente es el factor más importante y la razón principal de los movimientos de masas. Según Cruden \& Varnes (1996) los movimientos de material son por pendiente, bajo la influencia de la gravedad y Hauser (1994) indica que corresponden principalmente a procesos generados por la gravedad, lo cual provoca que una porción específica del terreno se desplace hacia cotas inferiores a la original. Es así, como las ponderaciones desarrolladas, que corresponde a un 64\% del algoritmo, confirman la importancia de estos factores condicionantes en la susceptibilidad del proceso. Igualmente aquellas áreas que presentan pendientes mayores a $20^{\circ}$ y con morfometria free faces, rectilíneo y declive representan el $92,3 \%$ del total cuantificado.

Para el factor vegetación, el escaso desarrollo resta estabilidad a las laderas y predispone una alta sensibilidad a la erosión hídrica. La generación del algoritmo de vigor en imagen Landsat, no establece análisis multitemporal de variable, por lo que está supeditada a la época de mayor cobertura vegetacional del área de estudio (diciembre). Según este parámetro estacional, la presencia de la cobertura vegetal es escasa, con $67,42 \%$ de cuantificación raster (cr), entre los rangos baja, muy baja y nula, por lo que son sectores inestables de material. Según Selby (1993), la vegetación contribuiría a disminuir el efecto erosivo sobre las laderas generadas por factores como el clima, propiedades del suelo y topografía. Existe un 32,58\% (cr) de áreas con muy alta y alta cobertura vegetal, debido exposiciones sur-suroeste y sureste, que presentan un 55,83\% (cr), lo que determina áreas de umbría.

En el factor geología, el ráster de susceptibilidad no diferenció las condiciones litológicas sobre todo del macizo rocoso meteorizado, que generan desprendimientos y caídas de rocas, por lo que los resultados del trabajo de campo mejoraron ostensiblemente el modelo, diferenciando con mayor precisión las susceptibilidades ráster que presentaron incongruencia con los datos de terreno. Es así, como la composición y granulometría del material, adquiere relevancia al ser determinante de las propiedades de resistencia del depósito y su estabilidad en laderas y para el caso de rocas o caracterización de partículas mayores en un suelo, la litología es un factor que influirá en la resistencia a la meteorización y alteración de la roca, por lo que este factor el análisis heurístico es esencial.

La clasificación de remociones en masa consideró movimiento, el tipo y material superficial comprometido. Varnes (1978) y Hauser (1994) consideran otros tipos de movimientos en su clasificación, como por ejemplo deslizamientos rotacionales $\mathrm{y}$ translacionales, los cuales no se pueden caracterizar con este modelo debido a su complejidad, tratamiento y análisis de investigación. Los resultados obtenidos mostraron el alto potencial de remociones en masa que existe para el área de estudio, no obstante no son concluyentes, ya que se necesita un mayor conocimiento sobre el funcionamiento de los diferentes tipos de remociones en masa y de las variables que condicionan su dinámica, sobre todo del factor desencadenante precipitación, siendo la variable más importante (Hauser, 1994). Otros modelos de susceptibilidad como Santacana et al. (2003), Mohammadi et al. 
(2014) y Dragicevic et al. (2015) consideran la variable precipitación. No obstante, los resultados del modelo son satisfactorios, teniendo en cuenta las limitaciones de información de imágenes Landsat y ASTER (resolución espacial $30 \mathrm{~m}$ ), condicionando la cartografía a una escala intermedia de planificación territorial, y de acuerdo con Paz Tenorio et al. (2017), quien indica la limitación de las fuentes cartográficas, compensando su modelo con diferentes resoluciones de trabajo, condicionando el dato en diferentes niveles de escala. Por lo tanto, el modelo de susceptibilidad a procesos de remociones en masa en rutas cordilleranas es una primera aproximación en la identificación, caracterización y determinación de estos procesos altamente dinámicos.

\section{Conclusiones}

Este estudio permite realizar un primer análisis de las remociones en masa en el área de estudio, debido a que se obtuvieron comportamientos de variables que inciden en su desencadenamiento. Las características tanto geográficas, geomorfológicas, geológicas y antrópicas del área de estudio, generan condiciones que favorecen el desarrollo de procesos morfogéneticos de remociones en masa, asociados a la influencia gravitacional, morfología abrupta, intervención antrópica, variabilidad altitudinal y climática. La susceptibilidad de generarse este proceso geodinámico es alto, con un 65,3\% de las áreas con susceptibilidades muy altas y altas del total cuantificadas. Las áreas de susceptibilidad alta y muy alta, se encuentran vinculadas principalmente a pendientes mayores a $20^{\circ}$, escasa cobertura vegetal, con exposición norte, noreste y noroeste, con morfología de cara libre (free faces), rocas altamente meteorizadas y fracturadas y altaintervención antrópica. Se desarrollan principalmente los tipos de remociones en masa de deslizamientos (23\%), desprendimientos ( $21,1 \%)$, flujos $(17,3 \%)$ y caóticos $(15,3 \%)$ de total cuantificado.

Aquellas zonas con susceptibilidad media, baja y muy baja se encuentran asociadas a pendientes planas y suaves $\left(0\right.$ a $\left.20^{\circ}\right)$, exposiciones bajas (Sur, Suroeste y Oeste), cobertura vegetal moderada y alta, desarrolladas en sectores de morfología de declive y convexidad, unidades litológicas estables con baja meteorización y cercanas a drenes. Estos presentan una susceptibilidad inferior de producir algún proceso de remociones enmasa.

Los procesos de remociones en masa con mayor actividad en el área de estudio son los deslizamientos, de cualquier tipo según la clasificación propuesta. Los flujos son lo que pueden provocar daños en la vía de comunicación, activados porcondicionantes: pendiente alta, erosión severa, nula cobertura vegetal, meteorización fina y el principal factor las precipitaciones. Se requiere modelo de susceptibilidad distinto, para este tipo de remoción en masa, derivado específicamente a geomorfología fluvial $\mathrm{y}$ estudio de precipitaciones (pluviales y nivales). El tipo de remoción en masa, que puede generar mayores daños en las vías de comunicación, es el desprendimiento o la caída de bloques por alta rapidez en su detonación y representar accidentes con posiblesconsecuencias fatales. La viabilidad, rapidez y facilidad para la obtención de datos, derivados en factores mediante la utilización del SIG, hace viable la manipulación de este modelo para rutas cordilleranas.

\section{Agradecimientos}

Los autores agradecen a Dirección de Planeamiento del Ministerio de Obras Públicas (MOP), por financiamiento de 
trabajo de campo e infraestructura y Mesa de trabajo de riesgos naturales MOP, región del Maule.

\section{Referencias}

Becerra, C. (2006). Análisis de riesgo natural por remociones en masa, carretera El Cobre, División El Teniente. Rancagua, Chile. Corporación Nacional del Cobre (CODELCO).

Becerra, C. (2013). Análisis de Susceptibilidad a procesos de Remociones en masa mediante Sistemas de Información Geográfica (SIG) y Teledetección en ruta internacional Paso Pehuenche, Sector Laguna del Maule. (Tesis para optar al título de Magister en Gestión Ambiental Territorial, Centro Geomática, Universidad de Talca, Chile). Recuperada de http:// dspace.utalca.cl/handle/1950/9714

Bonachea J. (2006). Desarrollo, aplicación y validación de procedimientos y modelos para la evaluación de amenazas, vulnerabilidad y riesgo debidos a procesos geomorfológicos. (Tesis para optar al grado de Doctor, Universidad de Cantabria, España). Recuperada de https://www.tdx. cat/handle/10803/10610

Cruden, D. M. \& Varnes, D.J. (1996). Landslide types and processes. En A.K. Turner \& R.Schuster (Eds.), Landslides, investigation and mitigation, Special report 247, pp. 36-75. Washington D.C.: Transportation Research Board. ISBN: 030906208X.

De Rurange, J. \& Becerra, C. (2008). Diagnóstico geomorfológico fluvial de desbordes de cauces y monitoreo de áreas específicas con riesgo natural por remociones en masa, carretera El Cobre, División El Teniente. Corporación Nacional del Cobre (CODELCO).
Dragićević, S., Lai, T., \& Balram, S. (2015). GIS-based multicriteria evaluation with multiscale analysis to characterize urban landslide susceptibility in data- scarce environments. Habitat international, 45(Part. 2), 114-125. https://doi. org/10.1016/j.habitatint.2014.06.031

Dirección de Planeamiento (DIRPLAN). (2014). Remociones en masa en sectores específicos, Ruta 115-CH, Paso Pehuenche. (Informe Técnico). Dirección de Planeamiento, Región del Maule.

Felicísimo, M. (1994). Parametric statistical method for error detection in digital elevation models. ISPRS journal of photogrammetry and remote sensing, 49(4), 29-33. https://doi. org/10.1016/0924-2716(94)90044-2

Hamza, T. \& Kumar, T. (2017). GIS based landslide hazard evaluation and zonation. A case from Jeldu District, Central Ethiopia. Journal of King Saud University - Science, 29(2), 151-165. https://doi.org/10.1016/j. jksus.2016.05.002

Parise, M. \& Jibson, R. (2000). A seismic landslide susceptibility rating of geologic units based on analysis of characteristics of landslides triggered by the 17 January, 1994 Northridge, California earthquake. Engineering geology, 58(3-4), 251-270. https://doi.org/10.1016/S0013-

7952(00)00038-7

Hauser, A. (1994). Remociones en masa en Chile. (mass wasting in Chile). International journal of rock mechanics and mining sciences \& geomechanics abstracts, 31(3), 159. https://doi.org/10.1016/01489062(94)90783-8

Mohammadi, A., Irani, A., \& Sorur, J. (2014). The preparation of landslide map by Landslide Numerical Risk Factor (LNRF) model and Geographic Information System (GIS). The Egyptian journal of remote 
sensing and space sciences, 17(2), 159-170. https://doi.org/10.1016/j.ejrs.2014.08.001

Paz Tenorio, J.A., González Herrera, R., Gómez Ramírez, M., \& Velasco Herrera J.A. (2017). Metodología para elaborar mapas de amenazas por procesos de remoción en masa, análisis del caso ladera sur de Tuxtla Gutiérrez, Chiapas. Investigaciones geográficas, 92. https://doi.org/10.14350/rig.52822

Ruff, M. \& Czurda, K. (2008). Landslide susceptibility analysis with a heuristic approach in the Eastern Alps (Vorarlberg, Austria). Geomorphology, 94(3-4), 314-324. https://doi.org/10.1016/j.geomorph.2006.10. 032

Sabokbar, F., Shadman, M., \& Tazik, E. (2014). Landslide susceptibility mapping using geographically-weighted principal component analysis. Geomorphology, 226, 15-24. https:// doi.org/10.1016/j.geomorph.2014.07.026

Santacana, N., Baeza, B., Corominas, J., De Paz, A., \& Marturiá, J. (2003). A GISbased multivariate statistical analysis for shallow landslide susceptibility mapping in La Pobla de Lillet area (Eastern Pyrenees, Spain). Natural hazards, 30(3), 281-295.

https://doi.org/10.1023/b:nhaz.00000071 69.28860 .80
Selby, M.J. (1993). Hillslope materials and processes. Second edition. Oxford university press.ISBN-13:978-0198741831. ISBN-10: 0198741839

Shadman, M., Rahimi, S., \& Jafar Beglou, M. (2014). PROMETHEE II and fuzzy AHP: an enhanced GIS-based land slide susceptibility mapping. Natural hazards 73(1), 77-95. https://doi.org/10.1007/ s11069-012-0523-8

VanWesten, C., Castellanos, E., \&Kuriakose, S. (2008). Spatial data for landslide susceptibility, hazard, and vulnerability assessment: an overview. Engineering geology, 102(3-4), 112-131. https://doi. org/10.1016/j.enggeo.2008.03.010

Varnes, D.J. (1978). Slope movement types and processes. R.L Schuster \& R.J Krizek, (Eds.) Landslides, analysis and control. Special report $\mathrm{N}^{\circ} 176$. Transportation research board, National academy of sciences (pp.11-33). Washington D.C.

Wang, J. \& Peng, X. (2009). GIS-base 0d landslide hazard zonation model and its application. Procedia earth and planetary science, 1(1), 1.198-1.204. https://doi. org/10.1016/j.proeps.2009.09.184 